\title{
KESUKSESAN SISTEM INFORMASI AKUNTANSI: DUKUNGAN MANAJEMEN PUNCAK DAN KEMAMPUAN SUMBER DAYA MANUSIA
}

\author{
Sakura Aulia $^{1}$, Ruhul Fitrios ${ }^{2 *}$, Adhitya Agri Putra ${ }^{3}$ \\ 1,2,3 Universitas Riau, sakuraaulia25@gmail.com; \\ ruhul.fitrios@lecturer.unri.ac.id*(Corresponding author); adhityaagri@lecturer.unri.ac.id
}

\begin{abstract}
ABSTRAK
Penelitian ini bertujuan untuk menguji pengaruh dukungan manajemen puncak dan kemampuan sumber daya manusia terhadap kesuksesan sistem informasi akuntansi pada organisasi perangkat daerah di kabupaten/kota di pesisir utara. Metode penelitian yang digunakan adalah metode analisis deskriptif dan kausalitas. Dalam penelitian ini populasi tersampel sebanyak 104 organisasi perangkat daerah. Analisis data yang digunakan dalam penelitian ini adalah Smart PLS, sedangkan data yang digunakan adalah kuesioner yang telah diisi oleh masing-masing Organisasi Perangkat Daerah (OPD). Hasil penelitian menyimpulkan bahwa dukungan manajemen puncak berpengaruh signifikan terhadap keberhasilan sistem informasi akuntansi dan kemampuan sumber daya manusia berpengaruh signifikan terhadap keberhasilan sistem informasi akuntansi. Implikasi pada penelitian ini adalah bahwa pengguna sistem informasi yang berkompeten akan menghasilkan sistem dan informasi yang berkualitas.
\end{abstract}

Kata kunci: dukungan manajemen puncak, kemampuan sumber daya manusia, dan kesuksesan sistem informasi akuntansi.

\begin{abstract}
This study examines the effect of top management support and human resource capabilities on the success of accounting information systems in regional organizations in districts/cities on the north coast. The research method used is the descriptive and causal analysis method. In this study, the sampled population was 104 regional organizations. Analysis of the data used in this study is Smart PLS, while the data used is a questionnaire that has been filled out by each Regional Apparatus Organization (OPD). The study results conclude that top management support has a significant effect on the success of the accounting information system and the ability of human resources has a significant effect on the success of the accounting information system. This research implies that competent users of information systems will produce quality systems and information.
\end{abstract}

Keywords: top management support, human resources ability, the successful of the accounting information system.

Naskah diterima : 13-11-2021, Naskah dipublikasikan : 30-11-2021 


\section{PENDAHULUAN}

Sistem informasi akuntansi adalah suatu sistem yang mengumpulkan, mencatat, menyimpan, dan memproses data untuk menghasilkan informasi bagi pengambil keputusan. (Romney \& Steinbart, 2018). Oleh karena itu, agar menghasilkan informasi yang akurat maka organisasi harus menjamin kesuksesan dari sistem informasi akuntansi.

Suatu sistem informasi yang sukses dapat dilihat dari relevansi, ketepatan waktu, dan keakuratan informasi masih merupakan kunci keberhasilan sistem informasi, bahkan ketika sistem informasi dan langkah-langkah keberhasilan sistem tumbuh semakin banyak dan kompleks (DeLone \& McLean, 2016). Keberhasilan pelaksanaan sistem informasi akuntansi (SIA) didefinisikan sebagai penerapan sistem informasi akuntansi yang sukses di bagian yang menjadi perhatian utama organisasi, digunakan oleh satu atau lebih pengguna yang merasa puas dan akan meningkatkan kualitas kinerjanya (Pairat, 2012).

Dengan meningkatnya kualitas Sistem Informasi Akuntansi (SIA) maka akan mampu meningkatkan Kinerja Organisasi Sektor Publik (Ni Made, dkk. 2017). Penelitian terdahulu yang berhasil membuktikan pengaruh kesuksesan sistem informasi terhadap kinerja organisasi (Laudon \& Laudon, 2020; Ni Made, dkk. 2017; Darmaningsih, 2017)

Namun kenyataannya, masih banyak penerapan sistem informasi yang belum berhasil, seperti adanya ketidakpatuhan dalam pengelolaan finansial negara karena kelemahan sistem informasi akuntansi dan pelaporan dengan detail pencatatan belum dilakukan atau tidak akurat, sistem informasi akuntansi dan pelaporan tidak memadai, serta sistem akuntansi dan pelaporan belum didukung Sumber Daya Manusia (SDM) memadai yang ditemui oleh Badan Pemeriksa Keuangan (BPK) pada tahun 2017.

BPK RI Perwakilan Riau memberikan beberapa catatan untuk diperbaiki dan disempurnakan kepada Kabupaten Meranti untuk laporan 2019, yaitu dalam penerapan aplikasi sistem akuntansi dalam penyajian laporan keuangan sesuai dengan standar akuntansi pemerintah, BPK RI Thomas Ipoeng masih menemukan beberapa akun yang belum sepenuhnya menggunakan aplikasi akuntansi atau masih dibuat secara manual.

Berdasarkan fenomena tersebut, banyak sekali permasalahan dalam kesuksesan informasi akuntansi, yaitu adanya ketidakpatuhan dalam pengelolaan finansial, pencatatan belum dilakukan atau tidak akurat, sistem informasi akuntansi dan pelaporan tidak memadai, sistem akuntansi dan pelaporan belum didukung SDM memadai, serta beberapa akun yang belum sepenuhnya menggunakan aplikasi akuntansi atau masih dibuat secara manual.

Banyak faktor yang dapat mempengaruhi kesuksesan sistem informasi akuntansi, diantaranya dukungan manajemen puncak, dan kemampuan sumber daya manusia. Dukungan manajemen dimaksudkan untuk memastikan bahwa sistem informasi menerima dana dan sumber daya yang cukup untuk kesuksesannya Laudon \& Laudon (2020). Penelitian terdahulu yang berhasil membuktikan pengaruh dukungan manajemen puncak terhadap keberhasilan sistem informasi akuntansi (Yenni Carolina, 2017).

Dukungan manajemen adalah salah satu faktor yang paling penting untuk memastikan efektivitas IA yang dalam gilirannya berdampak positif terhadap kinerja organisasi secara keseluruhan (Mohammed Bello, dkk. 2018). Penelitian terdahulu yang berhasil membuktikan pengaruh dukungan manajemen puncak terhadap kinerja organisasi (Haque \& Anwar, 2012; Bello, dkk. 2018; Dewi, dkk. 2017).

Komponen sistem lainnya yang mempengaruhi keberhasilan sistem adalah brainware/user (pengguna), yaitu orang yang menggunakan sistem tersebut (Romney \& Steinbart, 2018). Kemampuan SDM adalah kapasitas seseorang saat ini untuk melakukan berbagai tugas dalam suatu pekerjaan (Robbins \& Judge, 2020). Hasil penelitian yang berhasil 
membuktikan pengaruh kemampuan SDM terhadap kesuksesan sistem informasi akuntansi (Arzia biwi, dkk. 2015; Septianingrum, 2014; Utami, 2016).

Penelitian ini dimaksudkan untuk menguji pengaruh dukungan manajemen puncak dan kemampuan sumber daya manusia terhadap kesuksesan penerapan sistem informasi akuntansi OPD pada Pemerintah Kota/Kabupaten di Wilayah Pesisir Utara Provinsi Riau

\section{KAJIAN LITERATUR}

\section{Dukungan Manajemen Puncak}

Dukungan manajemen dimaksudkan untuk memastikan bahwa sistem informasi menerima dana dan sumber daya yang cukup untuk kesuksesannya (Laudon \& Laudon, 2020). Manajemen puncak memegang peranan penting dalam setiap tahap dalam siklus pengembangan sistem (information system development life cycle) yang meliputi perencanaan, perancangan dan implementasi, dukungan manajemen puncak meliputi penyusunan sasaran dan penilaian tujuan, mengevaluasi usulan proyek pengembangan sistem informasi, mendefinisikan informasi dan pemrosesan yang dibutuhkan, melalui review program dan rencana pengembangan sistem informasi (Kusuma \& Damayanthi, 2017).

Dong, et al. (2009) menyatakan bahwa dukungan manajemen puncak berkaitan dengan sumber daya adalah penyediaan dana yang diperlukan untuk hardware, software dan lainnya. Dari penjelasan di atas dapat disimpulkan, dukungan manajemen puncak merupakan dukungan yang diberikan dalam bentuk dana dan sumber daya dalam mengembangkan sistem informasi akuntansi oleh manajemen puncak agar tercapainya tujuan dan meningkatkan kinerja organisasi. Bocij, et al. (2015:43) menyatakan sistem informasi bisnis membutuhkan lima sumber daya dasar yaitu:

1). Sumber daya manusia. Sumber daya manusia termasuk pengguna sistem informasi dan mereka yang mengembangkan, memelihara, dan mengoperasikan sistem.

2). Sumber daya perangkat keras. Istilah 'sumber daya perangkat keras' mengacu pada semua jenis mesin, bukan hanya perangkat keras komputer.

3). Sumber daya perangkat lunak. Dengan cara yang sama, istilah 'sumber daya perangkat lunak' tidak hanya merujuk program komputer dan media tempat penyimpanannya. Istilah itu juga bisa digunakan untuk menggambarkan prosedur yang digunakan oleh orang-orang.

4). Sumber daya komunikasi. Sumber daya juga diperlukan untuk mengaktifkan sistem yang berbeda mentransfer data.

5). Sumber daya data. Sumber daya data menggambarkan semua data yang dapat diakses organisasi untuk, terlepas dari bentuknya.

\section{Kemampuan Sumber Daya Manusia}

Kemampuan adalah kapasitas seseorang saat ini untuk melakukan berbagai tugas dalam suatu pekerjaan (Robbins \& Judge, 2018). Kompetensi merupakan suatu karakteristik dari seseorang yang memiliki keterampilan (skill), pengetahuan (knowledge), dan kemampuan (ability) untuk melaksanakan suatu pekerjaan (Nurillah, 2014). Mahapatro (2010: 139) menyatakan keterampilan adalah kemampuan seseorang untuk melakukan sesuatu dengan baik. Pegawai yang tidak mempunyai pengetahuan yang cukup akan bekerja tersendat-sendat dan juga mengakibatkan pemborosan bahan, waktu, dan tenaga (Nurillah, 2014). Menurut Robbins dan Judge (2018) keahlian pemakai sistem informasi dapat dilihat dari:

1). Knowledge (pengetahuan), pengetahuan sebagai pemakai sistem informasi dapat dilihat dari: 
a) Memiliki pengetahuan mengenai sistem informasi akuntansi.

b) Memahami pengetahuan tugas dari pekerjaannya sebagai pemakai sistem informasi.

2). Ability (Kemampuan), kemampuan sebagai pemakai sistem informasi dapat dilihat dari:

a) Kemampuan menjalankan sistem informasi yang ada.

b) Kemampuan untuk mengekspresikan kebutuhan informasi.

3). Skill (Keahlian), keahlian sebagai pemakai sistem informasi dapat dilihat dari:

a) Keahlian dalam pekerjaan yang menjadi tanggung jawab.

b) Keahlian dalam mengekspresikan kebutuhan-kebutuhannya dalam pekerjaan.

\section{Kesuksesan Sistem Informasi Akuntansi}

Kesuksesan sistem informasi akuntansi digambarkan sebagai kesuksesan dalam pelaksanaannya, sebagaimana didefinisikan oleh Pairat (2012), yaitu: sebagai penerapan sistem informasi akuntansi yang sukses di bagian yang menjadi perhatian utama organisasi, yang digunakan oleh satu atau lebih pengguna yang merasa puas dan akan meningkatkan kualitas kinerjanya. Kesuksesan sistem informasi dapat dilihat dari relevansi, ketepatan waktu, dan keakuratan informasi atau kualitas informasi, dan ketika sistem informasi dan langkah-langkah keberhasilan sistem tumbuh semakin banyak dan kompleks (DeLone \& McLean, 2016). Monograf ini mengeksplorasi fondasi dan tren dalam definisi dan pengukuran keberhasilan sistem informasi (DeLone \& McLean, 2016).

Model pengukuran keberhasilan sistem informasi dikemukakan oleh DeLone \& McLean (2016) yang dikenal dengan D\&M Is Success Model, yaitu: (1) System Quality (kualitas sistem), (2) Information Quality (kualitas informasi), (3) User (penggunaan), (4) User Satisfaction (kepuasan pemakai), (5) Individual Impact (dampak individu), dan (6) Organizational Impact (dampak organisasi). Penelitian ini menggunakan kualitas sistem dan kualitas informasi sebagai indikator keberhasilan system.

Kualitas sistem informasi akuntansi adalah alat untuk mengukur kemampuan sistem informasi akuntansi dalam memproses data keuangan menjadi informasi yang berkualitas (Fitrios, dkk. 2018). Kualitas sistem meliputi: adaptability, availability, reliability, response time and usability (Delon \& McLean, 2003). Sedangkan kualitas informasi digambarkan melalui informasi yang akurat, tepat waktu, dan relevan yang dihasilkan oleh sistem informasi akuntansi tersebut (Laudon \& Laudon, 2020).

\section{Pengaruh Dukungan Manajemen Puncak Terhadap Kesuksesan Sistem Informasi Akuntansi}

Proyek sistem informasi lebih besar kemungkinannya gagal ketika ada partisipasi pengguna yang tidak memadai atau tidak tepat dalam proses pengembangan sistem, kurangnya dukungan manajemen, dan manajemen yang buruk dari proses implementasi (Laudon \& Laudon, 2020).

Beberapa hasil penelitian membuktikan pengaruh dukungan manajemen puncak terhadap kesuksesan sistem informasi akuntansi, yaitu: Komala (2012), pengetahuan manajer akuntansi dan dukungan manajemen puncak mempengaruhi kualitas sistem informasi akuntansi; hasil penelitian Jufri Darma, dkk (2018) menunjukkan bukti bahwa dukungan manajemen puncak dan efektivitas kepemimpinan mempengaruhi kualitas sistem informasi akuntansi keuangan.

H1: Dukungan Manajemen Puncak Berpengaruh Terhadap Kesuksesan Sistem Informasi Akuntansi 


\section{Pengaruh Kemampuan Sumber Daya Manusia Terhadap Kesuksesan Sistem Informasi Akuntansi}

Salah satu komponen sistem yang mempengaruhi keberhasilan sistem informasi akuntansi adalah brainware (user), yaitu orang yang menggunakan sistem tersebut (Romney \& Steinbart, 2018). Sistem informasi tidak akan berjalan jika tidak ada sumber daya manusia sebagai asset tertinggi untuk meningkatkan kegiatan yang dilaksanakan dalam suatu perusahaan. Pimpinan sebaiknya menyediakan panduan yang yang berhubungan dengan program aplikasi/ software yang digunakan agar karyawan mampu mengoperasikan program yang telah disediakan.dan pimpinan sebaiknya memberikan bantuan pada karyawan ketika karyawan menemukan kesulitan yang berhubungan dengan hardware (Kusuma \& Damayanthi, 2017).

Beberapa hasil penelitian membuktikan pengaruh kemampuan sumber daya manusia terhadap kesuksesan sistem informasi akuntansi. Fritrios (2016) menemukan bahwa dengan meningkatnya komitmen manajemen puncak dan pelatihan pengguna dapat meningkatkan sistem informasi akuntansi. Lestari, dkk. (2017) kemampuan personal, berpengaruh terhadap efektivitas sistem informasi akuntansi pada Lembaga Perkreditan Desa (LPD) Se-Kecamatan Sukasada. Faridah \& Noviyanti (2017), apabila Kemampuan Personal Pengguna Sistem Informasi Baik, maka akan dapat meningkatkan Kinerja Sistem Informasi Akuntansi. Suartika \& Widhiyani (2017), Semakin tinggi tingkat kemampuan teknik personal maka efektivitas penggunaan SIA akan semakin meningkat.

H2: Kemampuan sumber daya manusia berpengaruh terhadap kesuksesan penerapan sistem informasi akuntansi

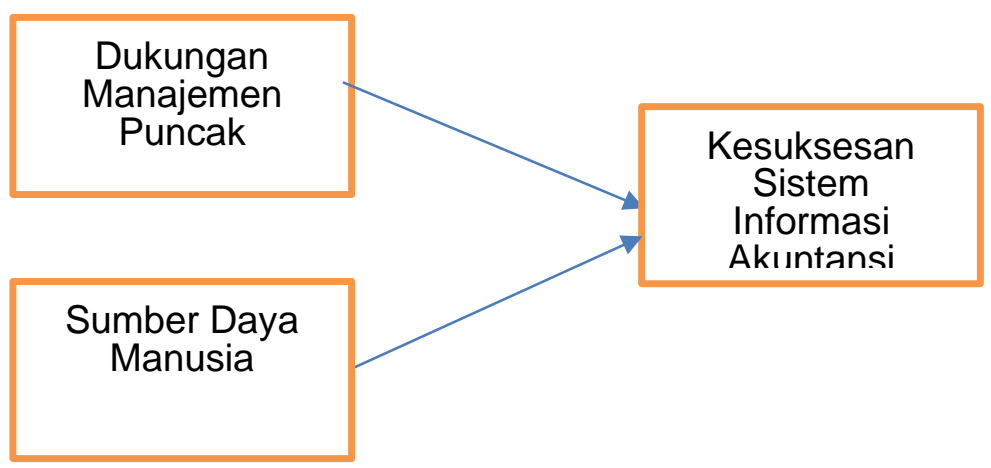

Gambar 1. Model Kerangka Pemikiran

\section{METODE PENELITIAN}

\section{Populasi, Sampel Penelitian dan Teknik Pengambilan Sampel}

Populasi adalah keseluruhan kelompok orang, peristiwa, atau hal-hal yang ingin diinvestigasi oleh peneliti (Sekaran \& Bougie, 2017). Sampel adalah subset atau sub kelompok dari populasi (Sekaran \& Bougie, 2017). Jumlah populasi OPD dimaksud adalah sebanyak 140 OPD. Dengan menggunakan rumus "Slovin" diperoleh jumlah sampel minimal sebanyak 104 OPD. Untuk menentukan sampel yang terpilih, digunakan teknik proportionate stratified random sampling. Proporsional alokasi sampel berdasarkan populasi digambarkan pada tabel 1. 
Tabel 1. Jumlah Populasi dan Sampel

\begin{tabular}{|c|l|c|c|}
\hline No & Prov/Kota/Kabupaten & Populasi & Sampel \\
\hline 1 & Kota Dumai & 29 & 22 \\
\hline 2 & Kabupaten Bengkalis & 32 & 24 \\
\hline 3 & Kabupaten Rokan Hilir & 26 & 19 \\
\hline 4 & Kabupaten Siak & 30 & 22 \\
\hline 5 & Kabupaten Meranti & 23 & 17 \\
\hline & Jumlah & 140 & 104 \\
\hline
\end{tabular}

\section{Data, Teknik Pengumpulan Data dan Pengembangan Instrumen}

Data yang digunakan dalam penelitian ini adalah data primer dan data sekunder. Data primer mengacu pada informasi yang diperoleh langsung (dari tangan pertama) oleh peneliti terkait dengan variabel ketertarikan untuk tujuan tertentu dari studi (Sekaran \& Bougie, 2017). Data sekunder mengacu pada informasi yang dikumpulkan dari sumber (Sekaran \& Bougie, 2017). Data primer penelitian ini dikumpulkan oleh peneliti bersumber dari jawaban responden atas kuesioner yang diberikan dan melalui wawancara. Sedangkan data sekunder penelitian ini bersumber dari buku-buku teks, jurnal-jurnal, dan media on-line yang digunakan sebagai bahan kajian teori, dan konsep serta hasil penelitian sebelumnya untuk membangun model penelitian.

Teknik pengumpulan data dalam penelitian ini adalah dengan kuesioner, yaitu daftar pertanyaan diajukan secara tertulis telah dirumuskan sebelumnya untuk dijawab oleh responden. Item-item pertanyaan dalam kuesioner didasarkan pada indikator-indikator yang ditemukan dari setiap variabel penelitian; dan menggunakan teknik wawancara yang digunakan untuk mendapatkan penjelasan lebih jauh atau untuk mengkonfirmasi terkait dengan jawaban kuesioner yang telah diberikan oleh responden yang belum dipahami atau belum lengkap. Kuesioner disampaikan kepada 104 OPD, dari jumlah itu sebanyak 89 OPD mengembalikan kuesioner dengan jumlah total 262 responden.

\section{HASIL DAN PEMBAHASAN}

\section{Analisis Deskriptif}

Berikut ini merupakan hasil dari analisis deskriptif:

Tabel 2. Analisis Deskriptif

\begin{tabular}{|l|l|l|l|l|l|l|}
\hline & Mean & Median & Min & Max & Standard Deviation & Kriteria \\
\hline DMP1 & 4,057 & 4,000 & 2,000 & 5,000 & 0,727 & Baik \\
\hline DMP1 & 4,057 & 4,000 & 2,000 & 5,000 & 0,727 & Baik \\
\hline DMP2 & 3,770 & 4,000 & 2,000 & 5,000 & 0,874 & Cukup \\
\hline DMP2 & 3,770 & 4,000 & 2,000 & 5,000 & 0,874 & Cukup \\
\hline DMP3 & 4,104 & 4,000 & 2,000 & 5,000 & 0,670 & Baik \\
\hline DMP3 & 4,104 & 4,000 & 2,000 & 5,000 & 0,670 & Baik \\
\hline DMP4 & 4,104 & 4,000 & 2,000 & 5,000 & 0,714 & Baik \\
\hline DMP4 & 4,104 & 4,000 & 2,000 & 5,000 & 0,714 & Baik \\
\hline
\end{tabular}


JURNAL AKUNTANSI, Vol. 10, No. 2, November (2021)

\begin{tabular}{|c|c|c|c|c|c|c|}
\hline & Mean & Median & Min & Max & Standard Deviation & Kriteria \\
\hline DMP5 & 4,037 & 4,000 & 2,000 & 5,000 & 0,786 & Baik \\
\hline DMP5 & 4,037 & 4,000 & 2,000 & 5,000 & 0,786 & Baik \\
\hline DMP6 & 4,090 & 4,000 & 2,000 & 5,000 & 0,766 & Baik \\
\hline DMP6 & 4,090 & 4,000 & 2,000 & 5,000 & 0,766 & Baik \\
\hline DMP7 & 3,898 & 4,000 & 1,670 & 5,000 & 0,808 & Cukup \\
\hline DMP7 & 3,898 & 4,000 & 1,670 & 5,000 & 0,808 & Cukup \\
\hline DMP8 & 3,894 & 4,000 & 1,670 & 5,000 & 0,879 & Cukup \\
\hline DMP8 & 3,894 & 4,000 & 1,670 & 5,000 & 0,879 & Cukup \\
\hline KSDM2 & 3,856 & 4,000 & 1,000 & 5,000 & 0,851 & Cukup \\
\hline KSDM2 & 3,856 & 4,000 & 1,000 & 5,000 & 0,851 & Cukup \\
\hline KSDM3 & 3,849 & 4,000 & 1,000 & 5,000 & 0,810 & Cukup \\
\hline KSDM3 & 3,849 & 4,000 & 1,000 & 5,000 & 0,810 & Cukup \\
\hline KSDM4 & 4,033 & 4,000 & 1,000 & 5,000 & 0,759 & Baik \\
\hline KSDM4 & 4,033 & 4,000 & 1,000 & 5,000 & 0,759 & Baik \\
\hline KSDM5 & 3,845 & 4,000 & 1,670 & 5,000 & 0,747 & Cukup \\
\hline KSDM5 & 3,845 & 4,000 & 1,670 & 5,000 & 0,747 & Cukup \\
\hline KSDM6 & 3,825 & 4,000 & 1,670 & 5,000 & 0,730 & Cukup \\
\hline KSDM6 & 3,825 & 4,000 & 1,670 & 5,000 & 0,730 & Cukup \\
\hline KSIA2 & 3,331 & 3,330 & 1,000 & 5,000 & 1,090 & Cukup \\
\hline KSIA2 & 3,331 & 3,330 & 1,000 & 5,000 & 1,090 & Cukup \\
\hline KSIA3 & 4,122 & 4,000 & 1,330 & 5,000 & 0,821 & Baik \\
\hline KSIA3 & 4,122 & 4,000 & 1,330 & 5,000 & 0,821 & Baik \\
\hline KSIA4 & 4,335 & 4,330 & 1,670 & 5,000 & 0,627 & Baik \\
\hline KSIA4 & 4,335 & 4,330 & 1,670 & 5,000 & 0,627 & Baik \\
\hline KSIA5 & 4,243 & 4,000 & 2,000 & 5,000 & 0,677 & Baik \\
\hline KSIA5 & 4,243 & 4,000 & 2,000 & 5,000 & 0,677 & Baik \\
\hline KSIA6 & 4,077 & 4,000 & 2,000 & 5,000 & 0,626 & Baik \\
\hline KSIA6 & 4,077 & 4,000 & 2,000 & 5,000 & 0,626 & Baik \\
\hline KSIA7 & 4,167 & 4,000 & 3,000 & 5,000 & 0,544 & Baik \\
\hline KSIA7 & 4,167 & 4,000 & 3,000 & 5,000 & 0,544 & Baik \\
\hline KSIA8 & 4,237 & 4,000 & 2,000 & 5,000 & 0,633 & Baik \\
\hline KSIA8 & 4,237 & 4,000 & 2,000 & 5,000 & 0,633 & Baik \\
\hline KSMD1 & 3,872 & 4,000 & 2,000 & 5,000 & 0,814 & Cukup \\
\hline
\end{tabular}


Hasil analisis deskriptif menggambarkan karakteristik mengenai variabel dukungan manajemen puncak, dan kemampuan sumber daya manusia, kesuksesan sistem informasi akuntansi, kinerja organisasi yang diteliti. Hasil ini sekaligus sebagai gambaran empiris untuk membuktikan fenomena penelitian. Di dalam mengukur variabel Dukungan manajemen puncak, terdapat delapan indikator yang menunjukkan rata-rata di atas 3 . Hal ini menunjukkan bahwa indikator untuk variabel dukungan manajemen puncak didominasi oleh kondisi baik yaitu di atas 4. Kemampuan sumber daya manusia, enam indikator menunjukkan kondisi yang cukup baik. Pada variable Kesuksesan Sistem Informasi Akuntansi, delapan indikator variabel menunjukkan rata-rata di atas 4 . Hal ini menggambarkan bahwa indikator Kesuksesan Sistem Informasi Akuntansi berada pada kondisi yang baik.

\section{Analisis Kausalitas}

\section{Evaluasi Model Pengukuran}

Internal consistency merupakan ukuran estimasi keandalan berdasarkan interkorelasi antar indikator variabel yang diobservasi. Keandalan diukur dengan menggunakan cronbach's alpha dan composite reliability (Hair 2014:136).

Tabel 3. Hasil Pengujian Reliabilitas

\begin{tabular}{|l|l|l|l|}
\hline & $\begin{array}{l}\text { Cronbach's } \\
\text { Alpha }\end{array}$ & rho_A & $\begin{array}{l}\text { Composite } \\
\text { Reliability }\end{array}$ \\
\hline DMP & 0,879 & 0,883 & 0,905 \\
\hline KSDM & 0,809 & 0,811 & 0,863 \\
\hline KSIA & 0,841 & 0,845 & 0,880 \\
\hline
\end{tabular}

Berdasarkan Tabel 3, untuk setiap variabel memiliki nilai Cronbach's Alpha dan Composite Reliability di atas 0,6. Oleh karena itu, dapat disimpulkan bahwa varabel memiliki indikator yang reliable atau andal.

Convergent validity ditentukan dengan menggunakan outer loading dan average variance extracted (AVE).

Tabel 4. Hasil Pengujian Validitas Outer Loading

\begin{tabular}{|l|c|c|}
\hline & $\begin{array}{c}\text { Original } \\
\text { Sample (O) }\end{array}$ & $\begin{array}{c}\text { Sample } \\
\text { Mean (M) }\end{array}$ \\
\hline Dukungan Manajemen Puncak & & \\
\hline DMP1 <- SDM & 0,901 & 0,903 \\
\hline DMP2 <- SDM & 0,896 & 0,892 \\
\hline DMP3 <- HW & 0,907 & 0,903 \\
\hline DMP4 <- HW & 0,918 & 0,920 \\
\hline DMP5 <- SW & 0,969 & 0,968 \\
\hline DMP6 <- SW & 0,968 & 0,967 \\
\hline DMP7 <- DANA & 0,959 & 0,960 \\
\hline DMP8 <- DANA & 0,951 & 0,948 \\
\hline
\end{tabular}


JURNAL AKUNTANSI, Vol. 10, No. 2, November (2021)

\begin{tabular}{|l|c|c|}
\hline & $\begin{array}{c}\text { Original } \\
\text { Sample (O) }\end{array}$ & $\begin{array}{c}\text { Sample } \\
\text { Mean (M) }\end{array}$ \\
\hline $\begin{array}{l}\text { Kemampuan Sumber Daya } \\
\text { Manusia }\end{array}$ & & \\
\hline KSMD1 <- KNOWLEDGE & 0,764 & 0,753 \\
\hline KSDM2 <- KNOWLEDGE & 0,919 & 0,920 \\
\hline KSDM3 <- ABILITY & 0,925 & 0,925 \\
\hline KSDM4 <- ABILITY & 0,920 & 0,919 \\
\hline KSDM5 <- SKILL & 0,945 & 0,944 \\
\hline KSDM6 <- SKILL & 0,946 & 0,945 \\
\hline $\begin{array}{l}\text { Kesuksesan Sistem Informasi } \\
\text { Akuntansi }\end{array}$ & & \\
\hline KSIA2 <- KS & 0,675 & 0,663 \\
\hline KSIA3 <- KS & 0,805 & 0,800 \\
\hline KSIA4 <- KS & 0,769 & 0,767 \\
\hline KSIA5 <- KS & 0,772 & 0,769 \\
\hline KSIA6 <- KI & 0,803 & 0,800 \\
\hline KSIA7 <- KI & 0,869 & 0,871 \\
\hline KSIA8 <- KI & 0,857 & 0,856 \\
\hline
\end{tabular}

Hasil Outer Loading pada Tabel 4 menunjukkan nilai masing-masing di atas 0,6. Hal ini dapat disimpulkan bahwa indikator memiliki validitas yang signifikan.

Tabel 5. Hasil Pengujian Validitas Average Variance Extracted (AVE)

\begin{tabular}{|l|l|}
\hline & (AVE) \\
\hline Dukungan Manajemen Puncak (DMP) & 0,655 \\
\hline Kemampuan Sumber Daya Manusia (KSDM) & 0,642 \\
\hline Kesuksesan Sistem Informasi Akuntansi (KSIA) & 0,573 \\
\hline
\end{tabular}

Hasil pengujian pada tabel 5 menunjukkan bahwa semua variabel memiliki nilai AVE di atas 0,5. Hal ini menunjukkan bahwa variable-variabel tersebut berdasarkan nilai AVE memiliki kriteria validitas yang baik. 
Tabel 6. Evaluasi Model Struktural

\begin{tabular}{|c|c|c|c|c|c|c|c|}
\hline & $\begin{array}{c}\text { Origina } \\
\text { l } \\
\text { Sample } \\
\text { (O) }\end{array}$ & $\begin{array}{c}\text { Sample } \\
\text { Mean } \\
\text { (M) }\end{array}$ & $\begin{array}{l}\text { Standard } \\
\text { Deviation } \\
\text { (STDEV) }\end{array}$ & $\begin{array}{c}\mathbf{T} \\
\text { Statistic } \\
\mathbf{S} \\
(\mid \mathbf{O} / \mathbf{S T} \\
\text { DEV } \mid) \\
\end{array}$ & $\begin{array}{c}\mathbf{P} \\
\text { Value } \\
\mathbf{S}\end{array}$ & $\begin{array}{c}\mathbf{R} \\
\text { Square }\end{array}$ & $\begin{array}{l}\text { Adjusted } \\
\text { R Square }\end{array}$ \\
\hline DMP -> KSIA & 0,345 & 0,375 & 0,148 & 2,318 & 0,021 & \multirow{2}{*}{0,334} & \multirow{2}{*}{0,318} \\
\hline KSDM -> KSIA & 0,322 & 0,301 & 0,157 & 2,047 & 0,041 & & \\
\hline
\end{tabular}

R Square menunjukkan bahwa nilai R Square Kesuksesan SIA sebesar 0,334. Hasil menunjukkan bahwa konstruks Dukungan Manajemen Puncak (DPM) dan Kemampuan Sumber Daya Manusia (KSDM) mampu menjelaskan Kesuksesan SIA sebesar 33\%, sedangkan sisanya sebesar $67 \% \%$ dijelaskan oleh variabel lain. Kategori untuk hasil R Square variabel Kesuksesan SIA berada diatas 0,25-0,50 dikategorikan sebagai moderate (Hair, 2014: 175).

\section{Uji Hipotesis}

Hasil uji hipotesis pada Tabel 6 menunjukkan bahwa $t$ statistic dari Dukungan Manajemen Puncak menghasilkan nilai 2,318 lebih besar dari 1,96 dengan $P$ value 0,021 lebih kecil dari 0,05. Hasil ini membuktikan bahwa Dukungan Manajemen Puncak berpengaruh terhadap kesuksesan sistem informasi akuntansi.

Selanjutnya $t$ statistic dari kemampuan sumber daya manusia menunjukkan nilai 2,047 lebih besar dari 1,96 dengan $P$ value 0,041 lebih kecil dari 0,05. Hasil ini membuktikan bahwa kemampuan sumber daya manusia berpengaruh terhadap kesuksesan sistem informasi akuntansi.

\section{Pembahasan}

\section{Pengaruh Dukungan Manajemen Puncak terhadap Kesuksesan Sistem Informasi Akuntansi}

Adanya pengaruh Dukungan Manajemen Puncak terhadap Kesuksesan sistem informasi akuntansi secara signifikan dibuktikan dengan hasil t hitung 2,318 yang lebih besar dari t table 1,96 dengan P Value 0,021. Besar pengaruh budaya organisasi terhadap kesuksesan sistem informasi akuntansi ditentukan oleh besar nilai dari Path Coefficient yaitu 0,345. Nilai statistik deskriptif menunjukan bahwa penyediaan hardware dan software memiliki nilai yang baik yang berhubungan dengan KSIA. Oleh karena itu, agar penerapan sistem informasi akuntansi yang sukses tercapai maka OPD perlu memperhatikan dukungan manajemen puncak dengan penyediaan hardware dan software, dan dukungan dana.

Hasil penelitian ini sejalan dengan hasil penelitian Hasil penelitian Jufri Darma, dkk (2018) menunjukkan bukti bahwa dukungan manajemen puncak dan efektivitas kepemimpinan mempengaruhi kualitas sistem informasi akuntansi keuangan. Meningkatnya sistem informasi akuntansi pada sebuah organisasi dapat disebabkan oleh kualitas sistem dan kualitas informasi yang baik. 


\section{Pengaruh Kemampuan Sumber Daya Manusia terhadap Kesuksesan Sistem Informasi Akuntansi}

Kemampuan SDM berpengaruh terhadap KSA. Hasil tersebut didapat setelah diperoleh t hitung 2,047 lebih besar dari t tabel 1,96 dengan P value 0,041. Sedangkan besarnya pengaruh Dukungan Manajemen Puncak terhadap Kesuksesan sistem informasi akuntansi ditentukan oleh nilai path coefficient sebesar 0,322. Semakin meningkatnya kemampuan SDM maka akan meningkat pula tingkat kesuksesan penerapan sistem informasi akuntansi.

Penelitian ini sesuai dengan Tjhai Fung Jen (2002) bahwa, semakin tinggi kemampuan teknik personal sistem informasi akuntansi, akan meningkatkan kinerja sistem informasi akuntansi. Suatu organisasi membutuhkan SDM yang memiliki knowledge, skill, dan ability agar dapat meningkatkan sistem informasi akuntansinya.

\section{PENUTUP}

\section{Simpulan}

Dukungan Manajemen Puncak mempengaruhi Kesuksesan Sistem informasi akuntansi OPD Kota/Kabupaten Wilayah Pesisir di Provinsi Riau. Terdapatnya dukungan manajemen puncak dalam memberikan fasilitas sehingga dapat memberikan kesuksesan pada Sistem Informasi Akuntansi. Kemampuan Sumber Daya Manusia mempengaruhi Kesuksesan sistem informasi akuntansi OPD Kota/Kabupaten Wilayah Pesisir di Provinsi Riau. Kemampuan Sumber Daya Manusia Yang baik pada setiap OPD dapat memberikan kesuksesan pada Sistem Informasi Akuntansi.

\section{Saran}

Saran untuk Pengembangan Ilmu agar $\mathrm{R}^{2}$ dalam penelitian selanjutnya dapat maksimal, maka disarankan agar menambahkan faktor lain dalam penelitian berikutnya. Bagi penelitian selanjutnya diharapkan sampel penelitian ini dapat diperluas ke seluruh Kabupaten di Provinsi Riau. Saran untuk pemecahan masalah, agar sistem informasi akuntansi dan informasi yang dihasilkan berkualitas, penting untuk meningkatkan dukungan manajemen puncak yang dicirikan dengan penyediaan hardware dan software, serta kemampuan Sumber Daya Manusia yang dicirikan dengan knowledge, skill, dan abillity.Agar meningkatkan kinerja organisasi yang berkualitas, maka penting untuk memperkuat kemampuan SDM yang dicirikan dengan knowledge, skill, dan abillity, serta memperkuat KSIA dicirikan dengan kualitas sistem dan informasi yang berkualitas.

\section{REFERENSI}

Bello, Suleiman Mohammed. 2018. Internal audit quality dimensions and organizational performance in Nigerian federal universities: the role of top management support. Journal of Business and Retail Management Research Vol. 13 Issue 1

Berliana, Vera. 2018. Analisis Pengaruh Self-efficacy, Kapabilitas, dan Perilaku Kerja Inovatif terhadap Kinerja. Jurnal Maksi Preneur Vol. 7 No. 2

Biwi, Arzia. 2015. Pengaruh Kapabilitas Personal Dan Dukungan Manajemen Puncak Terhadap Kinerja Sistem Informasi Akuntansi Pt. Tirta Mumbul Jaya Abadi Singaraja. Jurnal Akuntansi Volume 3 No. 1 
Bocij, Paul; Andrew Greasley and Simon Hickie. 2015, Business Information Systems Technology, Development and Management for the E-Business. Fifth edition. London: Pearson Education Limited

Carolina, Y. (2017). Analyzing the Effect of Top Management Support on Accounting Information System (AIS)Success. AdvanceScienceLetters, 23(11), 11625-11628

Darma, Jufri. 2018. The Role of Top Management Support In The Quality of Financial Accounting Information Systems. Journal of Applied Economic Sciences Volume 13 Issue 4(58)

Darmaningsih, Putu Dian. 2017. Pengaruh Sistem Informasi Akuntansi (Sia), Human Capital, dan Budaya Organisasi Tri Hita Karana Terhadap Kinerja Organisasi Pada Satuan Kerja Perangkat Daerah (Skpd) Dinas di Kabupaten Buleleng. Jurusan Akuntansi S1 Volume 7, No.1 Tahun 2017

DeLone, W. and E. R. McLean, 2016. Information System Success Measurement, Foundation and Trends in Information Systems, Vo. 2, Issue 1, Now Publisher Inc., Hanover US.

Destriyani, Vini. 2015. Pengaruh Good Governance, Kualitas Sumber Daya Manusia, Pemanfaatan Teknologi Informasi Dan Pengendalian Intern Terhadap Kinerja Organisasi (Studi pada Satuan Kerja Perangkat Daerah Kabupaten Kepulauan Meranti). Jurnal Ekonomi Vol. 2 No. 2

Dewi, Putu Sukma. 2017. Pengaruh Sistem Informasi Akuntansi dan Budaya Organisasi terhadap Kinerja Organisasi Hotel di Kabupaten Buleleng. Jurnal akuntansi Vol:7 No. 1 Tahun 2017

Dong, Linying: Derrick Neufeld and Chris Higgins. 2009, Top management support of enterprise systems implementations. Journal of Information Technology, 24, pp.55-80

Faridah, E., \& Noviyanti, R. 2017. Pengaruh Kemampuan Personal Pengguna Sistem Informasi Terhadap Kinerja Sistem Informasi Akuntansi (Studi Pada Pln Rayon Ciamis). Jurnal Wawasan dan Riset Akuntansi. Vol. 4. No. 2.

Fitrios, R., Fitrios, R., Susanto, A., Soemantri, R., \& Suharman, H. 2018. the Influence of Environment Uncertainly on The Accounting Information System Quality and its Impact on The Accounting Information Quality, Journal of Theoretical and Applied Information Technology, 96(21), 7164-7175.

Fitrios, R. 2016. Factors That Influence Accounting Information System Implementation And Accounting Information Quality. International Journal Of Scientific \& Technology Research Volume 5.

Hair, J., Hult, G., Ringle, C., \& Sarstedt, M. 2014. A Primier On Partial Least Squares Structural Equation Modeling (PLS-SEM). America: SAGE Publication, Inc.

Haque, Abdul \& Shamyla Anwar. 2012. Linking Top Management Support and IT Infrastructure with Organizational Performance: Mediating Role of Knowledge Application. Jurnal Sosial Sains Vol. 8, No. 1, 2012, pp. 121-129

Khamis, Amran M.Q. \& Dr. Ishwara. P. 2017. Top Management Support And Accounting Information System. Jurnal Internasional Penelitian dan Pengembangan Volume: 2 Issue: 11

Kinicki, Angelo, dan Mel Fugate. 2018. Organizational Behavior A Practical, Problem Solving Approach. Newyork: McGraw Hills Company. 
Komala, Adeh Ratna. 2012. The Influence of The Accounting Managers' Knowledge and The Top Managements' Support on The Accounting Information System and Its Impact on The Quality of Accounting Information: A Case of Zakat Institutions in Bandung. Jurnal Manajemen Global Volume 4. Number 1

Laudon, Kenneth C \& Laudon, J.P. 2020. Management Information Systems Managing the Digital Firm. 16th Edition. New York: Pearson Education Limited

Mahapatro, B.B., 2010. Human Resource Management, New Age International Publisher, New Delhi.

McShane, Steven L, dan Mary Ann Von Glinow. 2018. Organizational Behavior 8 th Ed. Newyork: McGraw Hills Company.

Moeheriono. 2010. Pengukuran Kinerja Berbasis Kompetensi. Cetakan kedua. Jakarta: Ghalia Indonesia

Niven, R Paul. 2008. Balanced Scorecard Step-By-Step For Government And Nonprofit Agencies Second Edition. ISBN 978-0-470-18002-0

Nurhazizal M, dkk. 2019. Pengaruh Komitmen Organisasi, Budaya Organisasi, Gaya Kepemimpinan dan Kompetensi SDM Terhadap Kinerja Pemerintah Desa: Good Governance Sebagai Pemediasi. Jurnal Akuntansi, Vol. 8, No.1

Nurillah. 2014. Pengaruh Kompetensi Sumber Daya Manusia, Penerapan Sistem Akuntansi Keuangan Daerah (SKAD), Pemanfaatan Teknologi Informasi Dan Sistem Pengendalian Intern Terhadap Kualitas Laporan Keuangan Pemerintah.(Studi Empiris Pada SKPD Kota Depok).

Pairat \& Pornpandejwittaya. 2012. Effectiveness of AIS: Effect on Performance of Thai-Listed Firms In Thailand, International Journal Of Business Research, July, 2012. Vol 12 Issue 3.

Kusuma, Pardani Kadek. \& Damayanthi, I Gst Ayu Eka. 2017. Pengaruh Pemanfaatan Teknologi, Partisipasi Pemakai, Manajemen Puncak Dan Kemampuan Pemakai Terhadap Efektivitas Sistem Informasi Akuntansi. Jurnal Akuntansi Universitas Udayana Vol.19.3

Rizqina, Zakiul Amri, dkk. 2017. Pengaruh Budaya Kerja, Kemampuan, dan Komitmen Kerja Terhadap Kepuasan Kerja Pegawai serta Dampaknya Terhadap Kinerja Badan Pengusahaan Kawasan Perdagangan Bebas dan Pelabuhan Bebas Sabang (Bpks). Jurnal Magister Manajemen Volume 1, No.1

Robbins, Stephen P. dan Judge, Timothy A. 2018. Essentials of Organizational Behavior. 14 ${ }^{\text {th }}$ Edition. Pearson Education: United States

Romney, Marshall B. dan Paul John Steinbart. 2018. Accounting Information System. Fourteenth Edition. Pearson Education Limit: New Jersey

Sekaran, Uma. dan Bougie, Roger. 2017. Metode Penelitian Bisnis, Edisi 6, Jakarta: Penerbit Salemba Empat

Septianingrum, Putri Aryani. 2014. Pengaruh Dukungan Top Management, Kemampuan Pengguna, Serta Adanya Pelatihan dan Pendidikan Pengguna Terhadap Kinerja Sistem Informasi Akuntansi (Studi Kasus Pada Bpjs Ketenagakerjaan Semarang Dan D.I Yogyakarta). Yogyakarta: Universitas Negeri Yogyakarta

Silitonga, P. Eddy Sanusi and Djoko Setyo Widodo. 2017. Analysis Of Organization Commitment and Competence To Jb Satisfaction and Organizational Performance At Bekasi City Goverrment. Int. J. Adv. Res, Vol 5, No. 7 
Sinambela, Lijan Poltak. 2012. Kinerja Pegawai Teori Pengukuran dan Implikasi. Yogyakarta: Graha Ilmu.

S. Lestari, Ni Made. Wahyuni, Made A. dan Yuniarta, Gede A. 2017. Pengaruh Partisipasi Pemakai Sistem Informasi, Kemampuan Personal, Pemanfaatan Teknologi Informasi, Dan Peran Pengawas Internal Terhadap Efektivitas Sistem Informasi Akuntansi Pada Lembaga Perkreditan Desa (Lpd) Se-Kecamatan Sukasada. Jurnal Akuntansi Volume 7 No 1 Tahun 2017

Suartika, K. A., dan Sari Widhiyani, N. L., 2017. Kemampuan Teknik Personal Pada Efektivitas Penggunaan Sistem Informasi Akuntansi Dengan Pendidikan dan Pelatihan Sebagai Pemoderasi. E-Jurnal Akuntansi Universitas Udayana, vol. 18. No.2; Februari 2017.

Trihapsoro, Argo. 2015. Pengaruh Kualitas Sumber Daya Manusia, Pemanfaatan Teknologi Informasi Dan Sistem Pengendalian Intern Pemerintah Terhadap Kinerja Pemerintah Daerah (Studi Pada Satuan Kerja Perangkat Daerah Kabupaten Boyolali). Boyolali: Universitas Muhammadiyah Surakarta.

Utami, Shendy Cahyaning, dkk. 2016. Pengaruh Kemampuan Pengguna Sistem Informasi, Keterlibatan Pengguna, dan Dukungan Manajemen Puncak Terhadap Kinerja Sistem Informasi Akuntansi pada Pt Btpn Area Surakarta.Jurnal Akuntansi dan Sistem Teknologi Informasi Vol. 12 No. 2 